\title{
Selective Decrease in Central Nervous System Serotonin Turnover in Children with Dopa-Nonresponsive Dystonia
}

\author{
BIRGIT ASSMANN, MARTIN KÖHLER, GEORG F. HOFFMANN, SIMON HEALES, AND \\ ROBERT SURTEES \\ Institute of Child Health, University College London, London WC1N 1EH, U.K. [B.A., M.K., R.S.]; \\ National Hospital for Neurology and Neurosurgery, London WC1N 3BG, U.K. [S.H.]; and Universitäts \\ Kinderklinik Heidelberg, D-69120 Heidelberg, Germany [B.A., G.F.H.]
}

\begin{abstract}
Childhood dystonia that does not respond to treatment with levodopa (dopa-nonresponsive dystonia, DND) has an unclear pathogenesis and is notoriously difficult to treat. To test the hypothesis that there may be abnormalities in serotonin turnover in DND we measured cerebrospinal fluid (CSF) concentrations of homovanillic (HVA) and 5-hydroxyindoleacetic (HIAA) acids, metabolites of dopamine and serotonin, respectively, in 18 children with dystonia not responsive to levodopa. These were combined with a reference population of 85 children with neurologic or metabolic disease known not to affect dopamine or serotonin metabolism. Because of the known natural age-related decrement in HVA and HIAA concentrations, the results were analyzed using multiple regression using age and DND as predictors of CSF HIAA and HVA concentrations. DND was a highly significant predictor of CSF HIAA concentration $(p<$ 0.001 ) but not of CSF HVA concentration $(p=0.59)$. After fitting a regression model, the geometric mean ratio of CSF
\end{abstract}

\section{ABSTRACT}

HIAA in DND compared with the reference range was 0.53 whereas that for CSF HVA was 0.95 . We also analyzed CSF HIAA/HVA ratios. After fitting a regression model, we found no dependence on age, and the mean of CSF HIAA/HVA in DND was 0.28 whereas that for the reference range was 0.49 ( $p<$ 0.001 ). We conclude that a significant number of children with DND have reduced CNS serotonin turnover. Treatment with drugs that increase serotonin concentration in the synaptic cleft should be considered in this group of patients. (Pediatr Res 52: 91-94, 2002)

CSF, cerebrospinal fluid

\section{Abbreviations}

HIAA, 5-hydroxyindoleacetic acid

HVA, homovanillic acid

DND, dopa-nonresponsive dystonia
Childhood dystonias can pragmatically be divided into those that respond to treatment with levodopa and those that do not. Those that do respond to levodopa usually have some parkinsonian features and have been termed parkinsonism-dystonia. Parkinsonism-dystonia syndromes are often caused by deficiency of the neurotransmitter dopamine resulting from inborn errors of the dopamine biosynthesis pathways $(1,2)$. Dystonia that does not respond to levodopa has a wide variety of causes, and its pathogenesis is poorly understood. Although the study of the acidic metabolites of dopamine and the individual pterin species in human CSF has been fruitful in understanding the mechanisms causing parkinsonism-dystonia in children and

Received December 11, 2000; accepted February 26, 2002.

Correspondence and reprint requests: R.A.H. Surtees, M.D., Neurosciences Unit, Institute of Child Health (UCLMS), 30 Guilford Street, London WC1N 1EH, U.K.; e-mail: R.Surtees@ich.ucl.ac.uk

Supported by a grant from the Deutsche Forschungsgemeinschaft (B.A.).

Current address (M.K.): Fachklinik Hohenstücken, Brahmsstrasse 38, D-14772 Brandenburg, Germany. young adults $(1,3-5)$, it has been disappointing in other movement disorders such as DND. This latter group of patients is also notoriously difficult to treat.

Serotonin and dopamine metabolism in the brain are closely linked at both a biochemical and at a physiologic level $(6,7)$. The basal ganglia of both animals and man have a large serotoninergic projection from the midbrain raphe nuclei $(8-$ 12). However, the function of this in the control of movement is not entirely clear. Impaired CNS serotonin metabolism has been found in adult-onset idiopathic focal dystonias (13). Rats depleted of serotoninergic neurons show no abnormality of baseline movement (14). Yet the genetically dystonic rat has diminished motor responses that involve serotoninergic systems and increased sensitivity to $5-\mathrm{HT}_{1 \mathrm{~A}}$ serotoninergic agonists (15), and the genetically dystonic hamster is dramatically worsened by $5-\mathrm{HT}_{1 \mathrm{~A}}$ antagonists (16). In humans, the serotonin syndrome is becoming increasingly recognized in patients taking drugs that increase synaptic serotonin or stimulate serotonin receptors $(17,18)$. This syndrome has a major motor 
component arising from basal ganglia dysfunction that includes dystonia (19). Thus, available evidence suggests a role for serotoninergic systems in the production of movement disorders of basal ganglia origin. Consequently, we investigated serotonin turnover in the CNS in children with DND.

\section{METHODS}

Of 149 consecutive CSF samples referred to a single laboratory for amine neurotransmitter analysis during a 2-y period, 27 referred to dystonia as part of the symptom complex. The case notes of these 27 children were examined between 1 and 3 y later to determine whether the dystonia was doparesponsive or not and also to obtain the final diagnosis. Dopanonresponsiveness was defined as no alleviation of dystonia despite treatment with full replacement doses of cocareldopa (levodopa/carbidopa; approximately $10 \mathrm{mg} / \mathrm{kg}$ body weight per day of levodopa) for at least 4 to $6 \mathrm{wk}$. Of the 27 children with dystonia, 21 were dopa-nonresponsive. Two children with glutaric aciduria type I and one with tyrosinemia type I who had DND were excluded because these are neurometabolic disorders that directly affect tryptophan and tyrosine metabolism, the precursors of serotonin and dopamine, respectively.

Eighteen patients with DND, aged 0.6 to $14.3 \mathrm{y}$ at the time of CSF sampling, were identified. Brief patient details are given in Table 1. Approval for the study was obtained from the Research Ethics Committee of the Institute of Child Health and Great Ormond Street Hospital for Children, and informed consent was obtained from the patients and their parents.

Concentrations of HVA and HIAA, stable acidic metabolites of dopamine and serotonin, respectively, were measured in each CSF sample by HPLC with coulometric electrochemical detection (7). All measurements were made on the first milli- liter of CSF collected. These were combined with a reference population of 85 children previously described (7).

The results, except for the CSF HIAA/HVA ratio, were logarithmically transformed to normalize the distributions. The effect of age, dystonia, and treatment as predictors of CSF HVA and HIAA concentrations and CSF HIAA/HVA ratios were examined by analysis of covariance. The magnitude of the effects was calculated by fitting multiple regression models and examining the individual partial regression coefficients. Statistical analyses were performed using SPSS for Windows software (SPSSUK Ltd, Woking).

\section{RESULTS}

Both age $\left(F_{1,102}=43, p<0.001\right)$ and DND $\left(F_{1,102}=16\right.$, $p<0.001)$ were highly significant predictors of CSF HIAA concentration, explaining almost $50 \%$ of its variability. The geometric mean ratio of DND to the reference range for CSF HIAA was 0.53 ( $95 \%$ confidence interval, 0.41 to 0.69 ; Fig. $1 A)$. By contrast, age $\left(F_{1,102}=39, p<0.001\right)$ but not DND $\left(F_{1,102}=0.29, p=0.59\right)$ was a highly significant predictor of CSF HVA concentration, explaining almost $40 \%$ of its variability. The geometric mean ratio of DND to the reference population for CSF HVA was 0.95 (95\% confidence interval, 0.82 to 1.21$)$. DND $\left(F_{1,102}=17, p<0.001\right)$ but not age $\left(F_{1,102}\right.$ $=1.0, p=0.31)$ was a highly significant predictor of CSF HIAA/HVA ratio, explaining almost $15 \%$ of its variability. The mean difference between DND and the reference population for CSF HIAA/HVA ratio was 0.22 (95\% confidence interval, 0.11 to 0.33 ; Fig. $1 B$ ).

Because of the small numbers, drug treatment was divided into two groups: antidystonic therapy (baclofen, acetazolamide, and trihexyphenidyl) and antiepileptic therapy (diaze-

Table 1. Brief clinical details and the results of biogenic amine metabolite analysis*

\begin{tabular}{|c|c|c|c|c|}
\hline $\begin{array}{l}\text { Age at LP } \\
\text { (y) }\end{array}$ & Final diagnosis & Treatment at LP & $\begin{array}{l}\text { CSF HIAA } \\
\text { (SND) }\end{array}$ & $\begin{array}{l}\text { CSF HVA } \\
\text { (SND) }\end{array}$ \\
\hline 13.7 & Post-HIE & $\begin{array}{l}\text { Baclofen } \\
\text { Acetazolamide }\end{array}$ & -0.9 & -0.6 \\
\hline 8.1 & HSS & None & -1.5 & -0.1 \\
\hline 4.2 & Post-HIE & $\begin{array}{l}\text { Phenobarbitone } \\
\text { Phenytoin }\end{array}$ & -1.0 & -0.1 \\
\hline 1.5 & HSS & None & -1.1 & -0.9 \\
\hline 4.7 & $\mathrm{CP}$ & None & -0.9 & +0.2 \\
\hline 10.4 & Unresolved & None & +0.6 & +0.6 \\
\hline 1.6 & Angelmann & None & -0.8 & +0.3 \\
\hline 9.1 & HSS & Carbamazepine & +0.7 & +0.4 \\
\hline 1.9 & Unresolved & None & -0.6 & +0.2 \\
\hline 13.5 & PKD & None & -1.6 & 0 \\
\hline 5.1 & Unresolved & Trihexyphenidyl & -0.8 & -0.3 \\
\hline
\end{tabular}

Abbreviations: LP, lumbar puncture; HIE, postnatal hypoxic-ischemic encephalopathy; PMD, Pelizaeus-Merzbacher disease; HSS, Hallervorden-Spatz syndrome; PCH, pontocerebellar hypoplasia; CP, cerebral palsy; PKD, paroxysmal kinesogenic dystonic choreoathetosis.

* Because of the natural age-related decrement in CSF HIAA and HVA, the results are given as the standard normal deviates (SND) for the age of the child by comparison with a published reference population from the same laboratory (7). 

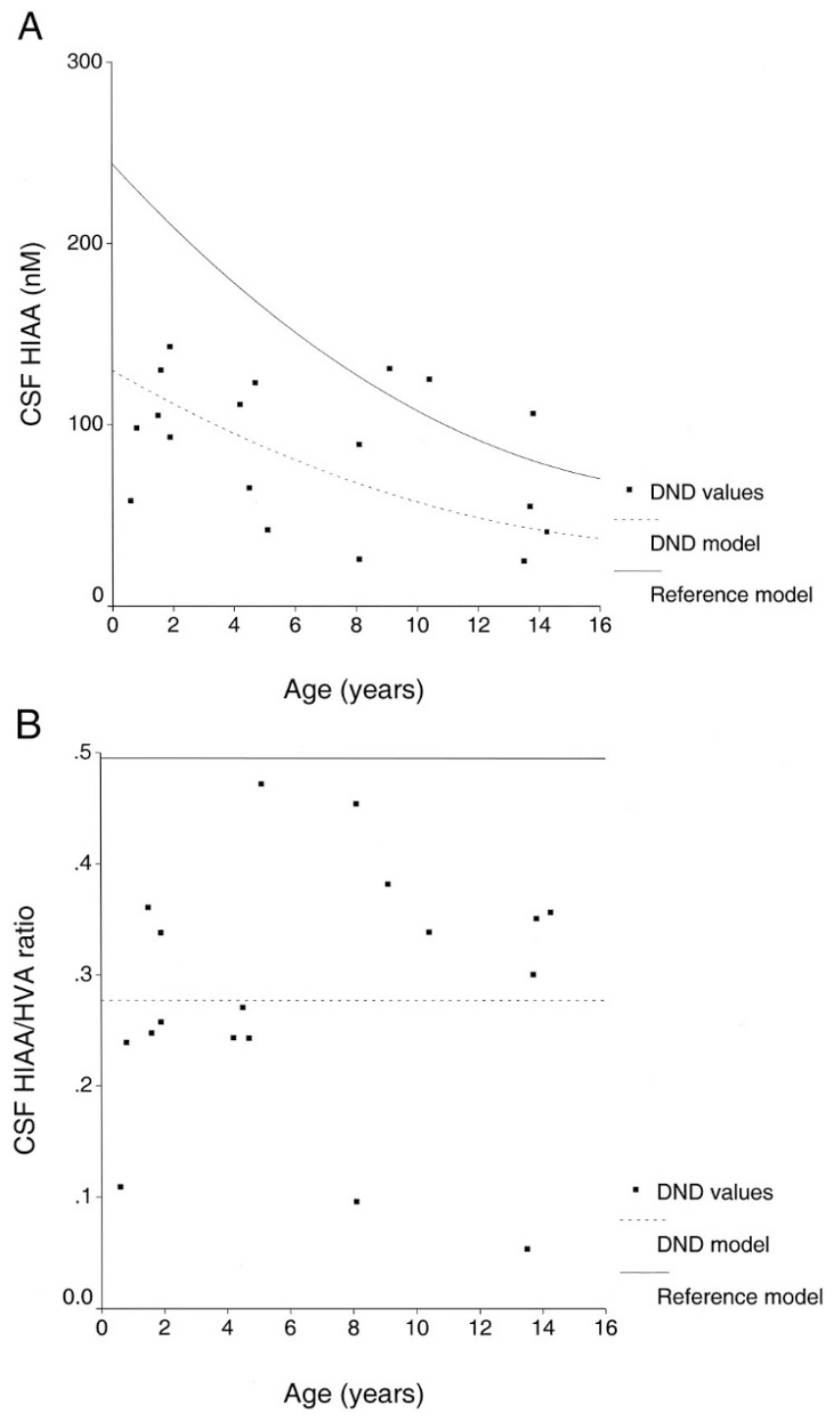

Figure 1. The fitted multiple regression model showing CSF concentrations of HIAA $(A)$ and CSF HIAA/HVA ratio $(B)$ in the reference population and children with DND plotted against age. The upper continuous line is the modeled mean value of CSF HIAA $(A)$ or HIAA/HVA ratio $(B)$ for the reference population; the lower discontinuous line is the modeled mean value for children with DND. Individual results from the children with DND are shown as the filled squares.

pam, phenobarbitone, phenytoin, and carbamazepine). There was no significant effect of drug therapy on either CSF HIAA $\left(F_{2,102}=0.26, p=0.77\right), \operatorname{CSF} \operatorname{HVA}\left(F_{2,102}=2.72, p=0.25\right)$, or CSF HIAA/HVA ratio $\left(F_{2,102}=2.34, p=0.20\right)$.

\section{DISCUSSION}

This study demonstrated a selective reduction in CSF HIAA concentrations to approximately $50 \%$ those of our reference population in children with DND. The results are of the same magnitude as those found in adults with idiopathic focal dystonia (13), conditions also generally dopa-nonresponsive. The concentration of HIAA in CSF has been shown to reflect serotonin turnover in the CNS $(20,21)$, and the marked rostrocaudal gradient suggests that most is generated in the brain
(7, 22-24). Our findings in DND therefore suggest reduced turnover of brain serotonin.

It is not too surprising that DND did not predict CSF HVA concentrations and that the ratio of the concentrations predicted in DND compared with the reference population was close to unity. The concentration of CSF HVA has been shown to reflect dopamine turnover in the brain $(7,20-22,24)$. The children studied here were selected for the lack of response to levodopa, which is the immediate precursor of dopamine that readily crosses the blood-brain barrier and enhances dopamine synthesis in neurons. Dopa-nonresponsiveness implies that presynaptic synthesis of dopamine is intact.

The natural decrement of CSF HIAA and HVA concentrations with age is well recognized $(7,25)$. This appears to be related to a combination of the rostrocaudal gradient and maturational changes in enzyme activity and cofactor availability (7).

The mechanisms underlying the selective decrease in serotonin turnover in DND are unclear. Because of the mix of final diagnoses, it is unlikely that specific defects in the synthesis, storage, and release of serotonin are involved. Approximately one third of the children studied had neurodegenerative disorders, and it is possible that there is serotoninergic tract degeneration. For instance, in Hallervorden-Spatz disease, the key pathology is present in the globus pallidus and substantia nigra pars reticularis (26), both of which receive serotoninergic projections (27).

Whatever the mechanisms, the reduced turnover of CNS serotonin may be important in the pathogenesis of dystonia and provide a rational basis for its treatment. There are now several ways of increasing serotonin concentration within the CNS. Giving the precursor 5-hydroxytryptophan or stimulating endogenous production with pyridoxine can enhance serotonin secretion, and selective serotonin reuptake inhibitors can block serotonin reuptake out of the synaptic cleft.

\section{REFERENCES}

1. Surtees R, Clayton P 1998 Infantile parkinsonism-dystonia: tyrosine hydroxylase deficiency. Mov Disord 13:350

2. Bandmann O, Valente EM, Holmans P, Surtees RA, Walters JH, Wevers RA, Marsden CD, Wood NW 1998 Dopa-responsive dystonia: a clinical and molecular genetic study. Ann Neurol 44:649-656

3. Hyland K, Surtees RA, Rodeck C, Clayton PT 1992 Aromatic L-amino acid decarboxylase deficiency: clinical features, diagnosis, and treatment of a new inborn error of neurotransmitter amine synthesis. Neurology 42:1980-1988

4. Hyland K 1993 Abnormalities of biogenic amine metabolism. J Inherit Metab Dis 16:676-690

5. Ludecke B, Knappskog PM, Clayton PT, Surtees RA, Clelland JD, Heales SJ, Brand MP, Bartholome K, Flatmark T 1996 Recessively inherited L-DOPA-responsive parkinsonism in infancy caused by a point mutation (L205P) in the tyrosine hydroxylase gene. Hum Mol Genet 5:1023-1028

6. Agren H, Mefford IN, Rudorfer MV, Linnoila M, Potter WZ 1986 Interacting neurotransmitter systems: a non-experimental approach to the 5HIAA-HVA correlation in human CSF. J Psychiatr Res 20:175-193

7. Hyland K, Surtees RA, Heales SJ, Bowron A, Howells DW, Smith I 1993 Cerebrospinal fluid concentrations of pterins and metabolites of serotonin and dopamine in a pediatric reference population. Pediatr Res 34:10-14

8. Nobin A, Bjorklund A 1973 Topography of the monoamine neuron systems in the human brain as revealed in fetuses. Acta Physiol Scand Suppl 388:1-40

9. Azmitia EC 1978 The serotonin-producing neurons of the midbrain median and dorsal raphe nuclei. Handb Psychopharmacol 9:233-314

10. Steinbusch HWM 1981 Distribution of serotonin-immunoreactivity in the central nervous system of the rat: cell bodies and terminals. Neuroscience 6:557-618

11. Azmitia EC, Gannon PJ 1986 The primate serotonergic system: a review of human and animal studies and a report on Macaca fascicularis. Adv Neurol 43:407-468

12. Molliver ME 1987 Serotonergic neuronal systems: what their anatomic organization tells us about function. J Clin Psychopharmacol 7:3S-23S 
13. Naumann M, Gotz M, Reiners K, Lange KW, Riederer P 1996 Neurotransmitters in CSF of idiopathic adult-onset dystonia: reduced 5-HIAA levels as evidence of impaired serotonergic metabolism. J Neural Transm 103:1083-1091

14. Plaznik A, Jessa M, Nazar M 1997 The behavioral effects of NMDA antagonists in serotonin depleted rats. Pharmacol Biochem Behav 58:159-166

15. Wieland S, Lucki I 1991 Altered behavioral responses mediated by serotonin receptors in the genetically dystonic (dt) rat. Brain Res Bull 26:11-16

16. Loscher W, Richter A 1994 The novel selective and silent 5-HT1A receptor antagonist (+)-WAY-100135 aggravates dystonic movements in a mutant hamster model Eur J Pharmacol 255:235-238

17. Mathew NT, Tietjen GE, Lucker C 1996 Serotonin syndrome complicating migraine pharmacotherapy. Cephalalgia 16:323-327

18. Leo RJ 1996 Movement disorders associated with the serotonin selective reuptake inhibitors. J Clin Psychiatry 57:449-454

19. Gerber PE, Lynd LD 1998 Selective serotonin-reuptake inhibitor-induced movement disorders. Ann Pharmacother 32:692-698

20. Moir AT, Ashcroft GW, Crawford TB, Eccleston D, Guldberg HC 1970 Cerebral metabolites in cerebrospinal fluid as a biochemical approach to the brain. Brain 93:357-368
21. Young SN, Garelis E, Lal S, Martin JB, Molina Negro P, Ethier R, Sourkes TL 1974 Tryptophan and 5-hydroxyindoleacetic acid in human cerebrospinal fluid. J Neurochem 22:777-779

22. Garelis E, Sourkes TL 1973 Sites of origin in the central nervous system of monoamine metabolites measured in human cerebrospinal fluid. J Neurol Neurosurg Psychiatry 36:625-629

23. Garelis E, Young SN, Lal S, Sourkes TL 1974 Monoamine metabolites in lumbar CSF: the question of their origin in relation to clinical studies. Brain Res 79:1-8

24. Sourkes TL, Young SN, Garelis E, Lal S 1975 Gradients of concentrations of tryptophan and 5- hydroxyindoleacetic acid (5-HIAA) in cerebrospinal fluid (CSF). Acta Vitaminol Enzymol 29:97-99

25. Brauetigam C, Wevers RA, Jansen RJ, Smeitink JA, de-Rijk-van-Andel JF, Gabreels FJ, Hoffmann GF 1998 Biochemical hallmarks of tyrosine hydroxylase deficiency. Clin Chem 44:1897-1904

26. Lowe J, Lennox G, Leigh PN 1997 Disorders of movement and system degenerations. In: Graham DI, Lantos PL (eds) Greenfield's Neuropathology. Arnold, London, pp 281-366

27. Tork I 1990 Anatomy of the serotonergic system. Ann N Y Acad Sci 600:9-34 